[Aus dem hygienischen Institut der Universität Königsberg i./Pr.]

\title{
Ueber die Kohlensäureverunreinigung der Luft in Zimmern durch Petroleumöfen.
}

Von

\author{
Dr. E. Babucke.
}

Die Frage, inwieweit die Luft in Wohnräumen durch Anwendung der bekannten Petroleumöfen verunreinigt wird, ist deshalb der Iösung wohl werth, da diese Oefen von vielen Seiten als äusserst praktisch und bequem empfohlen werden. Ihr Verbreitung ist keine geringe und ihre Anwendung in Badezimmern, Laboratorien und anderen kleinen Räumen sehr beliebt.

Neben der Beurtheilung des praktischen Werthes dieser Oefen wollen wir die Frage einer Kritik unterziehen, ob dieselben hygienisch unanfechtbar sind.

Wir haben durch die Kohlensäurebestimmung der Luft in der Regel ein bequemes Mittel, den Werth derselben für den menschlichen Organismus abzuschätzen. Als Grenzwerth der Kohlensäuremenge in Wohnräumen ist, abgesehen von der Kohlensäureproduction durch Heizung und Beleuchtung, 1 pro mille anzusehen.

Haben wir jedoch eine Heizung oder Beleuchtung, bei deren Einrichtung den Gasen kein Abzug nach aussen möglich ist, so findet eine Production von Kohlensäure statt, welehe eine directe Schädigung des menschlichen Organismus bewirken kann.

Lehmann ${ }^{1}$ hat in einer Tabelle folgende Werthe angegeben, welche von Emmerich, Friedländer und Herter festgestellt sind:

${ }^{1}$ Lehmann, Die Methoden der praktischen Hygiene. 1890. S. 175. Zeitschr. f. Hygiene. XXXII. 
Kohlensäureconcentration, die bei mehrstündiger Einwirkung nur minimale Symptome bedingt $=1$ Procent;

Kohlensäureconcentrationen, die noch $1 / 2$ bis 1 Stunde ohne schwerere Störung $z \mathfrak{n}$ ertragen sind $=$ bis 8 Procent;

Kohlensäureconcentrationen, die rasch gefährliche Erkrankungen bedingen $=$ ca. 30 Procent;

Wir wollen nun untersuchen, ob bei den Petroleumöfen ohne besondere Abführung der Gase die Menge der entwickelten Kohlensäure einen direct gesundheitsschädigenden Einfluss ausüben kannn.

Zur Ausführung der Versuche standen mir zwei Räume zur Verfügung, ein grösserer und ein kleiner von $12 \mathrm{cbm}$ Rauminhalt, welche durch eine Holzthür getrennt waren. Letzterer wurde zum Versuchszimmer bestimmt, da ich von der Voraussetzung ausging, dass gerade in solch kleinen Räumen ein Ofen ohne Abzug gefährlich werden könnte.

In dem kleinen Raum (1 Fenster, $12 \mathrm{cbm}$ Luftinhalt) wurde nun der Petroleumofen aufgestellt.

Derselbe ist von der Königsberger Firma J. W. Haack geliefert und besteht:

1. aus einem $35^{\prime \prime \prime}$ Blau-Bunsenbrenner,

2. einem durchgitterten Stativ von 62 om Höhe;

3. einem Wasserbehälter, welcher oben auf das Stativ gesetzt werden kann.

Durch die Thür, welche die beiden Räume trennt, wurden zwei rechtwinklig gebogene Glasröhren geführt, von denen eine durch das Schlüsselloch, die andere durch ein in die Thür gebohrtes Loch, in den grösseren Raum gingen. Die Bohrung wurde im oberen Drittel der Thür gemacht, so dass man nach Belieben sowohl vom Boden als auch aus den oberen Regionen des Versuchszimmers Luft entnehmen konnte.

Die in den Nebenraum ragenden Enden der Glasröhren waren mit Gummischläuchen versehen, welche durch Sperrhähne abgeschlossen waren. Die Kohlensäurebestimmung der Luft des Versuchszimmers geschah nach der Pettenkofer'schen Flaschenmethode.

Zu diesem Zweck wurden zwei Flaschen von bekanntem Inhalt mit doppelt durchbohrten Korken versehen, durch welche zwei Glasröhren gingen, die eine bis auf den Boden der Flasche, die andere nur knapp bis in das Gefäss.

Um nun aussehliesslich nur Luft des Versuchszimmers zu erhalten, füllte man die Flasche mit Wasser, verband das längere Glasrohr der Flasche mit dem Gummischlauch der aus dem Versuchszimmer kommenden Glasröhre. Nun kehrte man die Flasche um und liess das Wasser ausfliessen. 
Zur Bestimmung der Temperatur im Versuchszimmer war im unteren und oberen Theil desselben je ein Thermometer angebracht.

Ich lasse nun die Resultate meiner Versuche folgen:

\section{Versuch.}

Dauer der Heizung 2 Stunden.

Petroleumverbrauch 300 ecm.

Barometerstand 771.

Temperatur aussen $5^{0}$.

Temperatur im Vorzimmer $16^{\circ}$.

Temperatur im Versuchszimmer $\mathrm{v}$

ven $10^{\circ}$, unten $9^{\circ}$

$" \quad " \quad$ nach " $" \# 15^{\circ}, " 13^{0}$.

Kohlensäuregehalt der Luft im Versuchszimmer vor dem Versuch 0.7 pro mille.

Kohlensäuregehalt der Luft im Versuchszimmer nach 2 stündigem Brennen des Petroleumofens

im unteren Theil des Zimmers 1.2 pro mille,

$$
\text { " oberen " " " } 5.9
$$

Ofen schlecht brennend." Beim Oeffnen des Z̈immers starker Geruch nach Petroleum.

\section{Versuch.}

Dauer der Heizung 2 Stunden.

Petroleumverbrauch $300^{\mathrm{cem}}$.

Barometerstand $766^{\circ}$.

Temperatur aussen $6^{\circ}$.

Temperatur im Vorzimmer $17^{\circ}$.

Temperatur im Versuchszimmer vor der Heizung unten $8^{\circ}$, oben $11^{\circ}$, nach dem Versuch " $12^{\circ}, \# 18^{\circ}$.

Kohlensäuregehalt der Luft im Versuchszimmer vor dem Versuch 0.6 pro mille.

Kohlensäuregehalt der Luft im Versuchszimmer nach 1 stünd. Heizung unten $8 \cdot 5$, oben 11.0 pro mille,

Ofen "gut brennend. "Beim Oeffnen des "Zimmers schwacher Geruch nach Petroleum. Fenster verklebt.

\section{Versuch.}

Dauer der Heizung 2 Stunden,

Petroleumverbrauch $325^{\mathrm{cern}}$.

Barometer 755 .

Temperatur aussen $1^{0}$.

Temperatur im Vorzimmer $16^{0}$.

Temperatur im Versuchszimmer vor der Heizung unten $5^{\circ}$, oben $8^{0}$, " " nach " " $" 9^{\prime \prime}, " 18^{\circ}$. Kohlensäuregehalt der "Luft im Versuchszimmer vor der Heizung 0.5 pro mille. 
Kohlensäuregehalt der Luft im Versuchszimmer nach 1 stünd. Heizung unten 2, oben 10.8 pro mille,

Ofen sehr gut" brennend. Beim Oeffnen des Versuchszimmers kaum wahrnehmbarer Geruch nach Petroleum.

Dem Versuch war eine starke Lüftung des Versuchszimmers voransgegangen.

\section{Versuch.}

Dauer der Heizung 1 Stunde.

Petroleumverbrauch $120^{\mathrm{cm}}$.

Barometer 765.

Temperatur aussen $3^{\circ}$.

Temperatur im Vorzimmer $18^{\circ}$.

Temperatur im Versuchszimmer vor der Heizung unten $10^{\circ}$, oben $15^{\circ}$, nach " $", 11^{\circ}, \quad, 19^{\circ}$. Kohlensäuregehalt der Luft im Versuchszimmer vor der Heizung $0 \cdot 7$ pro mille.

Kohlensäuregehalt der Luft im Versuchszimmer nach 1 stünd. Heizung unten $3 \cdot 4$, oben $10 \cdot 4$ pro mille.

Die Thür zwischen Vor- und Versuchszimmer hat vor dem Versuch längere Zeit offen gestanden.

Ofen gut brennend. Kein Geruch nach Petroleum am Ende des Versuches.

\section{Versuch.}

Dauer der Heizung 1 Stunde.

Petroleumverbrauch $110^{\mathrm{cem}}$.

Barometer 760 .

Temperatur aussen $2^{0}$.

Temperatur im Vorzimmer $16^{0}$.

Temperatur im Versuchszimmer vor der Heizung unten $5^{\circ}$, oben $8^{\circ}$, $" \quad " \quad$ nach " $" \quad 77^{\circ}, \quad 12^{\circ}$. pro mille.

Kohlensäuregehalt der Luft im Versuchszimmer vor der Heizung 0.6

Kohlensäuregehalt der Luft im Versuchszimmer nach 1 stünd. Heizung unten 3 , oben 9.8 pro mille.

Ofen gut brennend. Schwacher Geruch nach Petroleum am Ende des Versuches.

VI. Versuch.

Dauer der Heizung 2 Stunden.

Petroleumverbrauch $200 \mathrm{~cm}$.

Barometer 756 .

Temperatur aussen $-6^{0}$.

Temperatur im Vorzimmer $16^{\circ}$.

Temperatur im Versuchszimmer vor der Heizung unten $1 \frac{1}{2}$, oben $5^{0}$, $" \quad " \quad$ nach $", \quad, 3, \quad " 10 \%$. 
Kohlensäuregehalt der Luft im Versuchszimmer vor der Heizung 0.4 pro mille.

Kohlensäuregehalt der Luft im Versuchszimmer nach 2 stünd. Heizung unten 4.5 , oben $9 \cdot 9$ pro mille.

Ofen sehr gut brennend. Kein Geruch nach Petroleum am Ende des Versuches.

Vor dem Versuch starke Ventilation des Versuchszimmers durch Zugluft.

\section{Versuch.}

Dauer der Heizung 5 Stunden.

Petroleumverbrauch $600 \mathrm{cem}$.

Barometer 761.

Temperatur aussen $-5^{\circ}$.

Temperatur im Vorzimmer $16^{\circ}$.

Temperatur im Versuchszimmer vor der Heizung unten 0 , oben $3^{0}$, nach " $" \quad 71 / 2, " 14^{\prime}$. Kohlensäuregehalt der Luft im Versuchszimmer vor der Heizung 0.4 pro mille.

Kohlensäuregehalt der Luft im Versuchszimmer nach 5 stünd. Heizung unten $4 \cdot 8$, oben $12 \cdot 3$ pro mille.

Ofen sehr gut brennend. Kein Geruch nach Petroleum am Ende des Versuches. Heizung.

Kräftige Ventilation des Versuchszimmers bis kurz vor Anfang der

$$
\text { VIII. Versuch. }
$$

Dauer der Heizung 6 Stunden.

Petroleumverbrauch $750^{\mathrm{cem}}$.

Barometer 760 .

Temperatur aussen $5^{\circ}$.

Temperatur im Vorzimmer $15^{\circ}$.

Temperatur im Versuchszimmer vor der Heizung unten 3 , oben $5^{0}$, Kohlensäuregehalt der Luft im Versuchszimmer vor der Heizung 0.5 pro mille.

Kohlensäuregehalt der Luft im Versuchszimmer nach 6 stünd. Heizung unten $5 \cdot 3$, oben $12 \cdot 0$ pro mille.

Ofen gut brennend. Kein Geruch nach Petroleum.

Lüftung vor dem Versuch.

IX. Versuch.

Dauer der Heizung 4 Stunden.

Petroleumverbrauch $480 \mathrm{~cm}$.

Barometer 765 .

Temperatur aussen $3^{0}$.

Temperatur in Vorzimmer $15^{\circ}$.

Temperatur im Versuchszimmer vor der Heizung unten 8, oben $10^{\circ}$, $" \quad " \quad$ nach $" \#, 12, " 16^{\circ}$. 
Kohlensäuregehalt der Luft in Versuchszimmer vor der Heizung 0.7 pro mille.

Kohlensäuregehalt der Luft im Versuchszimmer

nach 4 stünd. Heizung unten $4 \cdot 0$, oben $11 \cdot 5$ pro mille.

Ofen gut brennend. Kein Geruch nach Petroleum.

Vor dem Versuch hat die Verbindungsthür zwischen Versuchszimmer und Vorzimmer längere Zeit offen gestanden.

\section{Versuch.}

Dauer der Heizung 3 Stunden.

Petroleumverbrauch $380 \mathrm{~cm}$.

Barometer 764 .

Temperatur aussen $3^{0}$.

Temperatur im Vorzimmer $16^{\circ}$.

Temperatur im Versuchszimmer vor der Heizung unten 5, oben $8^{\circ}$,

" $"$ nach " $"$ " $"$, $14^{\circ}$.

Kohlensäuregehalt der Luft im Versuchszimmer vor" der Heizung 0.5 pro mille.

Kohlensäuregehalt der Luft im Versuchszimmer

nach 3 stünd. Heizung unten $3 \cdot 5$, oben $10 \cdot 0$ pro mille.

Ofen ohne Petroleumgeruch brennend.

Temperatur- und Kohlensäuretabelle sämmtlicher Versuche.

\begin{tabular}{|c|c|c|c|c|c|c|c|c|c|c|c|}
\hline \multirow{2}{*}{ 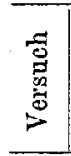 } & \multirow{2}{*}{ 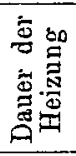 } & \multirow{2}{*}{ 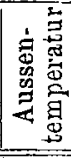 } & \multicolumn{4}{|c|}{$\begin{array}{l}\text { Temperatur } \\
\text { im Versuchzimmer } \\
\text { vor d. Vers. } \| \text { nach d. Vers. }\end{array}$} & \multicolumn{2}{|c|}{$\begin{array}{l}\text { Diff.zwischen } \\
\text { Anfangs- und } \\
\text { Endtemper. }\end{array}$} & \multicolumn{3}{|c|}{$\begin{array}{c}\text { Kohlensänregehalt } \\
\text { des Versuchszimmers } \\
\text { vor d. } \| \text { nach d. Vers. }\end{array}$} \\
\hline & & & unten & oben & unten & oben & unten & oben & & unten & $\overline{\text { ober }}$ \\
\hline I & 2 Std & $5^{\circ}$ & $9^{0}$ & 10 & 13 & 15 & $4^{0}$ & $5^{0}$ & $0.7 \%$ & $1 \cdot 2$ & 0.4 \\
\hline II & & 6 & 8 & 11 & & & & & 0.6 & 10. & 12 \\
\hline III & $2 "$ & 1 & 5 & 8 & & & & 10 & $\cdot$ & & \\
\hline IV & $1 "$ & 3 & 10 & 15 & 11 & & & & 0. & & 10 \\
\hline $\mathrm{v}$ & $1 "$ & 2 & 5 & 8 & & & & 4 & 0.6 & 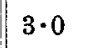 & 9 \\
\hline VI & $2 "$ & -6 & $1 \%$ & j & 3 & $10^{1} / 8$ & $11 / 2$ & $51 / 2$ & 0.4 & 4. & 9 \\
\hline VII & 5 & -5 & 0 & 3 & $71 / 2$ & 14 & 71 & 11 & 0.4 & $4 \cdot$ & 12 \\
\hline III & 6 & 5 & 3 & 5 & 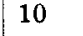 & 1 & 7 & 1 & 0.5 & 5. & 12 \\
\hline IX & 4 & 3 & 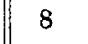 & 10 & . & 1 & 4 & 6 & 0.7 & 4 & 11 \\
\hline$x$ & 3 & 3 & 5 & 8 & 8 & 14 & 3 & 6 & 0.5 & $3 \cdot 5$ & $10 \cdot 0$ \\
\hline
\end{tabular}

Bevor ich auf das Ergebniss dieser Versuche eingehe, will ich noch zwei Arbeiten, welche in dieses Gebiet gehören, erwähnen. Die erste ist von Dr. Siebelt-Flins,berg ${ }^{1}$, die zweite rom Oberstabsarzt Dr. Krocker."

1 Siebelt, Mittheilung über die Verwendbarkeit der Petroleumheizöfen für Hotels und Logirhäuser. .Der 26. schlesische Bädertag. S. 43.

${ }^{2}$ Krocker, Ueber Petrolenmöfen. Militärärztliche Zeitsclerift. 1896. Nr. 2. 
In der ersten Arbeit sind annāhernd genaue Bestimmungen der Kohlensäureproduction angestellt, in der zweiten vermisse ich solche überhaupt. Siebelt bestimmte die Kohlensäuremenge der Luft folgendermaassen:

„50 cem Calciumhydratlösung (Kalkwasser) wurden durch Zusatz eines Tropfen Phenolphtaleĩn-Lösung roth gefärbt. Darauf wurde mit Hülfe der Wasserluftpumpe ein Luftstrom durch die Lösung geleitet, und zwar war der Versuch so angeordnet, dass in der Mlinute 500 cru Luft angesaugt wurden."

Je nach der Entfärbung der Lösung bestimmte Siebelt den Kohlensäuregehalt der durchgeleiteten Luftmenge.

Nach dieser Methode fand Siebelt in einem kleinen Zimmer von $30^{\mathrm{cbm}}$ Rauminhalt nach einstündiger Heizung durch einen Petroleumofen die Kohlensäuremenge im Vergleich zum Kohlensäuregehalt der Luft vor dem Versuch $(0.3$ pro mille) verdreifacht, nach 2 Stunden verfünffacht. Wurden die Versuche dagegen in einem Zimmer von $50^{\mathrm{ctm}}$ Rauminhalt angestellt, so betrug die Menge der Kohlensäure nach 1 Stunde das $11 / 2$ fache, nach 2 Stunden das Doppelte des Normalen.

Krocker äussert sich über diesen Punkt folgendermaassen:

„Mit einem Abzugsrohr werden Petroleumöfen im Interesse der Wärmeausnutzung nicht versehen. Die Beimischung der Verbrennungsproducte zur Zimmerluft erscheint auch unbedenklich, sofern die Verbrennung eine vollständige ist, d. h. wenn der Ofen geruchlos brennt."

$\mathrm{Ob}$ diese Behauptung durch eigene Experimente bestätigt wurde, ist aus der Arbeit nicht zu sehen.

Was uun den Heizeffect anbetrifft, so stellte Siebelt fest, dass mit dem von ihm angewandten Universalofen der Firma Hirschborn-Berlin die Temperatur des Zimmers in der ersten Brennstunde um $5^{0}$ bis $6^{\circ}$ gesteigert werden könne, von da ab findet ein langsamerer Anstieg statt, doch könnte die Temperatur zwischen $13^{\circ}$ und $14^{\circ}$ gehalten werden. Krocker macht keine Angaben über die Temperaturerhöhung.

Siebelt hält den Petroleumofen ,für ein gutes Aushülfs- oder Ergänzungsmittel, da wo die Kohlenheizung nicht anwendbar oder gelegentlich nicht ausreichend ist." In ganz ähnlicher Weise äussert sich Krocker, welcher die Petroleumöfen ,zur Ergänzung anderweitiger Heizvorrichtungen und zur vorübergehenden Erwärmung“ für sehr geeignet hālt.

Das Ergebniss meiner Versuche ist folgendes:

Wie schon vorher erwähnt, wurde zum Versuchszimmer ein kleiner Raum von $12^{\mathrm{cbm}}$ Luftinhalt gewählt. Ich glaube kaum, dass für die Praxis kleinere Räume in Betracht kommen. Kleine Laboratorien, Bade- 
zimmer, Wärterbuden u. s. w. haben für gewöhnlich einen jedenfalls nicht kleineren Rauminhalt. Meine Versuche geben also Resultate (abgesehen von der Temperatur), welche nur im ungünstigsten Falle in Wirklichkeit eintreten.

Die Temperatursteigerung betrug in den ersten Stunden im Durchschnitt $4^{0}$ und stieg dann langsam höher. Befriedigende Temperaturen wurden erzielt, wenn schon eine gewisse Temperatur im Versuchszimmer bestand.

Dies zeigt sich hauptsäehlich bei Versuch IV. Der hohen Endtemperatur von $11^{\circ}$ und $19^{\circ}$ entsprechen ziemlich hohe Anfangstemperaturen von $10^{\circ}$ und $15^{\circ}$.

Aber auch bei den Versuchen mit niedriger Anfangstemperatur waren die Heizeffecte nicht ungünstige, wenn man bedenlt, wie schwer ein Zimmer mit niedriger Temperatur durch Ofenheizung nait Brennmaterialien zu durchwärmen ist.

Aus den Versuchen ergiebt sich, dass durch die Petroleumheizung doch Temperaturen erzielt werden können, die den Aufenthalt in Räumen, welche vorher unbenutzbar waren, möglich machen.

Ich will allerdings nicht unterlassen, ein-Bedenken hier geltend zu machen. Der sehr milde Winter hatte Verhältnisse geschaffen, die den Temperaturbestimmungen sehr günstig waren.

Ob diese Oefen bei scharfer Kälte hinreichend heizen, muss ich deshalb dahingestellt sein lassen.

Bedenklicher sieht es mit der Verschlechterung der Luft durch die Petroleumheizung aus.

Hier sehen wir, dass bei allen Versuchen die Normalkohlensäuremenge von 1 pro mille (cf. 2) schon nach kurzer Zeit überschritten wird, und im Laufe der Heizung ergeben sich Kohlensäuremengen, welche bei längerer Einwirkung auf den Organismus, wenn auch nicht gesundheitsschädigende Einflüsse, so doch sicher Unbehagen bedingen würden.

Man sieht aus der Tabelle, dass die Luft im unteren Theil des Zimmers am wenigsten mit Kohlensäure durchmischt wird, dass die oberen Regionen dagegen die Maximalwerte anfweisen. In Versuch II dagegen ist auch im unteren Theil des Zimmers schon nach zwei Stunden eine bedeutende Kohlensäuremenge vorhanden. Bei diesem Versuch waren die Fenster mit Wattestreifen verdichtet, so dass die Poren- und Ritzenventilation stark behindert war.

Jedenfalls ist in solch' kleinen Räumen, wie das Versuchszimmer es ist, eine Petroleumheizung mit einer Kohlensäurereproduction verbunden, welche einen längeren Aufenthalt für unräthlich erscheinen lässt. Wir müssen uns aber sagen, dass dieses auch die ungünstigsten Verhältnisse 
sind, welche in der Praxis bestehen. Denn Räume von dieser Kleinheit werden meistens nur zu vorübergehendem Aufenthalt gebraucht.

Was schliesslich die Kosten der Heizung anlangt, so sind dieselben gering. Der Ofen verbraucht stündlich ca. $120 \mathrm{~cm}$ Petroleum. Also bei 8 stündiger Brenndauer würde ungefähr 1 Liter Petroleum verzehrt werden $=$ ca. 20 Pfennig.

Ich kann also nach meinen Versuchen die Petroleumöfen zwar nicht als das Ideal einer Heizung bezeichnen, jedoch zur Aushülfe und zur vorübergeheuden Heizung erscheinen sie mir in gewissen Grenzen geeignet.

Zum Schlusse sei es mir gestattet, meinem verehrten Chef, Herrn Professor v. Esmarch, für das Interesse, das er meinen Versuchen entgegen brachte, den verbindlichsten Dank auszusprechen. 